\title{
Association between serum concentrations of hexachlorobenzene and polychlorobiphenyls with thyroid hormone and liver enzymes in a sample of the general population
}

\author{
M Sala, J Sunyer, C Herrero, J To-Figueras, J Grimalt
}

Environmental and Respiratory Research Unit, Institut Municipal d'Investigació Mèdica, C/ Doctor Aiguader 80, 08003 Barcelona, Spain M Sala

J Sunyer

Department of Dermatology, Hospital Clínic i Provincial de Barcelona, Barcelona, Spain

C Herrero

Department of Environmental Chemistry CID-CSIC, Barcelona, Spain J Grimalt

Department of Toxicology, Hospital Clínic i Provincial de Barcelona, Barcelona, Spain

J To-Figueras

Correspondence to:

Dr J Sunyer

jsunyer@imim.es

Accepted 19 October 2000

\begin{abstract}
Objectives-Hexachlorobenzene (HCB) is a highly lipophilic organochlorine compound of widespread environmental occurrence, that accumulates in the biological system. It affects the porphyrine metabolism, thyroid hormones, and the liver function in animals. Although HCB is one of the most common organochlorine compound in humans, little investigation on its health effects has been done. Polychlorobiphenyls (PCBs) are also widespread toxic environmental contaminants. The aim of the present study was to investigate the association of serum HCB and PCB concentrations with thyroid hormone status and liver enzymes in human.
\end{abstract}

Methods-Thyroid stimulating hormone (TSH), total and free thyroxine (T4), aspartate aminotransferase (AST), alanine aminotransferase (ALT) and $\gamma$-glutamyltransferase (GGT) were measured as biological markers of thyroid and liver function in a rural population sample older than 14 years $(n=192$, except for TSH with $n=608$ ) highly exposed to HCB. Serum concentrations of HCB were measured by gas chromatography coupled to electron capture detection.

Results-After adjustment for confounding variables, there was a significant negative association between serum HCB concentrations and total T4 (a decrease of $0.32 \mu \mathrm{g} / \mathrm{dl}$ per each unit, ln $\mathrm{ng} / \mathrm{ml}$, of increase of $\mathrm{HCB}$ ) and a positive association with GGT (a relative increase of $\mathbf{1 0}$ $\%$ per each ln unit of increase of HCB), although most subjects $(92 \%)$ were within the normal range for both T4 and GGT. These associations were not modified after adjustment for total lipid content or for other organochlorine compounds. The association of T4 and GGT with PCB was smaller although significant. No association was found with the other biochemical markers.

Conclusions-These results suggest that the internal dose of HCB of this population may reflect a subtle metabolic effect on thyroid function and an enzymatic induction activity. Further studies are needed to evaluate the health impact of these effects in more susceptible populations, such as infants.

(Occup Environ Med 2001;58:172-177)
Keywords: hexachlorobenzene; environmental exposure; thyroid; liver enzymes

Hexachlorobenzene (HCB) is an organochlorine compound widespread in the environment, formerly used as fungicide. Nowadays, the main source of HCB is industrial emission as a byproduct of the manufacture of chlorinated solvents and pesticides. Hexachlorobenzene is highly lipophilic and accumulates in biological systems. Recently it has been suggested that HCB should be classified as a dioxin-like compound because it binds to the aryl-hydrocarbon (Ah) receptor, resulting in dioxin-like effects and bioacumulates. ${ }^{1}$

In animals, HCB has similar effects to those described for dioxins and polychlorobiplenyls (PCBs). It has been reported to induce hepatic and thyroid neoplasm, ${ }^{23}$ porphyria, ${ }^{45}$ and hormonal disruption, including alterations in progesterone and testosterone concentrations, ${ }^{67}$ depletion of triiodothyronine (T3) and thyroxine (T4), ${ }^{8}$ goitre, ${ }^{9}$ and hypothyroidism. ${ }^{10}$ Very little information on effects on liver function is available, although effects on hepatic $\gamma$-glutamyl transpeptidase have been described in rats. ${ }^{11}$

Although HCB is one of the most common organochlorine compound in humans, little investigation on its health effects in humans has been done. Most data are related to the accidental exposure in Turkey, between 1955 and 1959, when people consumed wheat grain treated with HCB for use as seed grain. In this incident, disturbances in porphyrin metabolism, leading to porphyria cutanea tarda, enlarged liver, enlargement of the thyroid gland, and osteoporosis or arthritis were found, primarily in children. ${ }^{412}$ Unfortunately, no information on serum or tissue HCB concentrations arose from this outbreak. The incidence of cancer in this population was never properly investigated.

A general population cross sectional study in a village, from a rural area, of 5000 inhabitants, located in the vicinity of an organochlorine compound factory (Flix, Catalonia, Spain), highly exposed to HCB due to airborne and occupational exposure, has been carried out. ${ }^{13}$ Mean serum concentration of $\mathrm{HCB}$ in this general population was $36.7 \mathrm{ng} / \mathrm{ml}^{13}$ which is the highest ever described. Results of a study of health effects showed that chronic exposure to HCB did not affect the general health of this general population, but suggested that specific 
health effects - such as cancer or Parkinson's disease-measured by questionnaire, could occur in factory workers, who were the most exposed subjects. ${ }^{14}$ Damage by environmental chemicals, including potential endocrine disrupters, most often is not visible or expressed as a clinically relevant disease, but they may cause loss of function. ${ }^{15}{ }^{16}$ In this population, however, no evidence of disturbances in porphyrin metabolism was found. ${ }^{17}$ We report here the assessment of the association between HCB in the serum samples of Flix inhabitants, and thyroid stimulating hormone (TSH), free and total T4, aspartate aminotransferase (AST), alanine aminotransferase (ALT) and $\gamma$-glutamyltransferase (GGT) as specific laboratory markers of thyroid and liver function. These enzymes have never been assessed in a general population sample highly exposed to hexachlorobenzene. Also, we assess the association between the same markers and PCBs due to their toxicity, although the concentrations of PCBs in Flix were similar to those in other locations.

\section{Population and methods}

A total of 608 subjects older than 14 years (249 men and 359 women, mean age 48.8 years) provided $40 \mathrm{ml}$ of blood and 24 hour urine. Collection of serum samples was not done in any particular fasting state. Details of the selection of the subjects have been reported elsewhere. ${ }^{14}$ Briefly, subjects in a random sample of the general population older than 14 years were asked to provide biological samples $(\mathrm{n}=328,42.1 \%$ response rate) and to answer a questionnaire administered by trained interviewers about residence, occupation, lifestyle, and medical history. Also, from the rest of this general population, 280 subjects $(7 \%)$ also provided biological samples and completed the questionnaire because they volunteered to do so for their own interest. Previous written consent for inclusion in the study was obtained in all cases. No differences in socioeconomic, occupational, and health status, nor in HCB concentrations, were found between subjects from the random samples and volunteers. Concentrations of HCB in serum were analyzed in all samples by gas chromatography coupled to electron capture detection (GC-

Table 1 Characteristics of the study population. Flix, Catalonia, Spain

\begin{tabular}{|c|c|c|c|}
\hline & Men & Women & Total \\
\hline \multicolumn{4}{|l|}{ Age $(\mathrm{n}(\%))$ : } \\
\hline $15-44$ & $(40.6)$ & $(44.0)$ & $(42.6)$ \\
\hline $45-64$ & $(34.1)$ & $(34.8)$ & $(34.5)$ \\
\hline$>64$ & $(25.3)$ & $(21.1)$ & $(22.9)$ \\
\hline Total & 249 & 359 & 608 \\
\hline Smokers ${ }^{\star}(\mathrm{n}(\%))$ & $(40.2)$ & (17.3) & $(26.6)$ \\
\hline Drinkers† (n (\%)) & $(55.8)$ & $68 \quad(18.9)$ & $(34.0)$ \\
\hline Loss of weight (n (\%)) & $18 \quad(7.3)$ & $31 \quad(8.7)$ & $49 \quad(8.1)$ \\
\hline $\mathrm{BMI}\left(\mathrm{kg} / \mathrm{m}^{2}\right)($ mean $(\mathrm{SD}))$ & $25.7(3.4)$ & $24.9(4.2)$ & $25.3(3.9)$ \\
\hline \multicolumn{4}{|c|}{ HCB and PCB levels (ng/ml) by occupational $\ddagger$ status: } \\
\hline Never workers (n (\%)) & $83(33.3)$ & $338 \quad(94.2)$ & $421 \quad(69.2)$ \\
\hline HCB (mean (SD)) & $14.1(25.5)$ & $17.5(14.2)$ & $16.8(17.1)$ \\
\hline PCBs (mean (SD)) & $3.4(3.7)$ & $3.2(3.0)$ & $3.2(3.1)$ \\
\hline Ever workers (n (\%)) & $166 \quad(66.7)$ & $21 \quad(5.8)$ & $187 \quad(30.8)$ \\
\hline HCB (mean (SD)) & $89.3(190.2)$ & $18.8(8.3)$ & $81.4(180.5)$ \\
\hline PCBs (mean (SD)) & $7.2(13.2)$ & $3.2(3.0)$ & $6.7(12.5)$ \\
\hline
\end{tabular}

*Smoke one or more cigarrete a day for $\geqslant 6$ months. †Drink $\geqslant 4$ alcoholic drinks a month.

‡Ever $v$ never workers in the electrochemical factory.
ECD) as previously described. ${ }^{18}$ Polychlorobiphenyls (summation of $28,52,101,118,138$, 153 , and 180 congeners) were also assessed due to their potential effects on thyroid and liver enzymes. Negative ion chemical ionisation GC coupled to mass spectrometry (GC-MS) was used to confirm the presence of these compounds in the samples. Validity of measurements was confirmed by a calibration between laboratories.$^{14}$

Thyroid stimulating hormone was measured in all serum samples $(n=608)$ in the reference laboratory of Catalonia. Total and free T4, AST, ALT, GGT, and total cholesterol and triglycerides were measured by this laboratory in a subset of 192 serum samples. This subset included all current workers from the electrochemical factory $(n=86,75$ men and 11 women) and a random sample of never workers $(\mathrm{n}=106 ; 17$ men and 89 women). Total cholesterol and triglycerides were used for calculation of total serum lipids and correction of the concentrations of organochlorinated compounds as described by Phillips et al. ${ }^{19}$

\section{STATISTICAL ANALYSIS}

Multiple linear regression models were fitted to assess the association between HCB and PCB concentrations in serum, and TSH, total and free T4, AST, ALT, and GGT, adjusting for possible confounders, which included sex, age, body mass index (in $\mathrm{kg} / \mathrm{m}^{2}$ ), recent loss of weight (10\% of weight in the last 12 months), alcohol consumption (habitual drinkers versus never drinkers and in $\mathrm{g}$ alcohol), smoking habits and occupation in the electrochemical factory (ever versus never workers in the electrochemical factory of this rural village). Continuous variables were included in the models centred by the mean. Occupation in the factory was found to be the main variable related to $\mathrm{HCB}$ serum concentrations in this population. ${ }^{13}$ Serum HCB and PCB concentrations were included and categorised into quartiles. They were also analyzed as a continuous variable. Models were fitted with serum concentrations of organochlorine both uncorrected and corrected for total serum lipid content. The distributions of TSH, AST, ALT, GGT, HCB, and PCB were skewed to the right, thus natural logarithmic transformations of these variables were used in the statistical analysis. Correlation plots and Pearson coefficients between HCB and markers of liver and thyroid function were also considered. A p value of 0.05 was taken as the cut off point for significance.

\section{Results}

The characteristics of the study population are presented in table 1 . Among men, $66.7 \%$ were or had been workers in the electrochemical factory. Few women $(5.8 \%)$ had worked in the factory, most of them in the administrative department. ${ }^{12}$ In all subjects HCB and PCB were found and were significantly higher among men who had been workers in the factory. The HCB concentrations in subjects who had never worked in the electrochemical plant 
Table 2 Description of serum concentrations of thyroid stimulating hormone (TSH), thyroxine (total T4 and free T4), aspartate aminotransferase (AST), alanine aminotransferase (ALT), glutamyl transpeptidase (GGT) by sex and occupation in Flix, Catalonia, Spain

\begin{tabular}{|c|c|c|c|c|}
\hline & \multicolumn{2}{|l|}{ Men } & \multicolumn{2}{|l|}{ Women } \\
\hline & Ever worker & Never worker & Ever worker & Never worker \\
\hline TSH $(n=608)(n)$ & 166 & 83 & 21 & 338 \\
\hline Median (range) & $1.2(0.0-3.5)$ & $1.5(0.2-29.3)$ & $1.5(0.7 ; 5.3)$ & $1.4(0.0-36.9)$ \\
\hline Age (adjusted mean) & 1.2 & 1.3 & 1.6 & 1.3 \\
\hline$\%>5 \mu \mathrm{lU} / \mathrm{ml}^{\star}$ & 0.6 & 1.2 & 4.5 & 2.1 \\
\hline Total T4 $(\mathrm{n}=192)(\mathrm{n})$ & 75 & 17 & 11 & 89 \\
\hline Median (range) & $6.4(2.9-9.8)$ & $7.1(5.0-10.0)$ & $5.5(3.8-7.7)$ & $7.4(4.2-11.3)$ \\
\hline Age (adjusted mean) & 6.2 & 7.1 & 6.2 & 7.7 \\
\hline$\%<4.7 \mu \mathrm{g} / \mathrm{dl}^{\star}$ & 14.7 & 0 & 27.3 & 1.1 \\
\hline \multicolumn{5}{|l|}{ Free T4 $(n=192)$ : } \\
\hline Median (range) & $1.3(0.9-1.8)$ & $1.4(1.1-2.0)$ & $1.2(1.0-1.3)$ & $1.3(0.8-1.7)$ \\
\hline Age (adjusted mean) & 1.3 & 1.4 & 1.2 & 1.3 \\
\hline$\%<0.8 \mathrm{ng} / \mathrm{dl}^{\star}$ & 0 & 0 & 0 & 0 \\
\hline \multicolumn{5}{|l|}{$\operatorname{AST}(n=192):$} \\
\hline Median (range) & $21 \quad(9.0-34.0)$ & $23.0(14.0-35.0)$ & $19.0(15.0,22.0)$ & $19.0(11.0-33.0)$ \\
\hline Age (adjusted mean) & 21.2 & 22.4 & 19.0 & 18.9 \\
\hline$\%>38 \mathrm{IU} / 1^{\star}$ & 0 & 0 & 0 & 0 \\
\hline \multicolumn{5}{|l|}{$\operatorname{ALT}(n=192):$} \\
\hline Median (range) & $13.0(6.0-49.0)$ & $11.0(6.0-50.0)$ & $10.0(6.0,16.0)$ & $10.0(5.0-38.0)$ \\
\hline Age (adjusted mean) & 10.1 & 11.8 & 9.9 & 10.1 \\
\hline$\%>33 \mathrm{IU} / 1^{\star}$ & 5.3 & 5.9 & 0 & 1.1 \\
\hline \multicolumn{5}{|l|}{ GGT $(n=192):$} \\
\hline Median (range) & $23.0(9.0-255.0)$ & $17.0(11.0-44.0)$ & $13.0(9.0-32.0)$ & $15.0(8.0-110.0)$ \\
\hline Age (adjusted mean) & 26.2 & 17.5 & 15.0 & 15.2 \\
\hline$\%>50 \mathrm{IU} / 1(\mathrm{men})^{\star}$ & 17.3 & 0 & - & - \\
\hline$\%>35 \mathrm{IU} / 1$ (women) $)^{\star}$ & - & - & 0 & 3.4 \\
\hline
\end{tabular}

*Reference values: TSH 0.25-5 $\mu \mathrm{IU} / \mathrm{ml}$; Total T4, 4.7-12.4 $\mu \mathrm{g} / \mathrm{ml}$; Free T4, 0.8-2.0 ng/dl; AST, 10-38 UI/1; ALT, 7-33 UI/1; GGT in men, $10-50 \mathrm{UI} / 1$; GGT in women, 5-35 UI/1.

(mean $16.8 \mathrm{ng} / \mathrm{ml}$ ) were still higher than those reported in the general population in other studies. ${ }^{12}$

Table 2 shows the population distribution of the laboratory markers of thyroid and liver function by sex and occupation in the electrochemical factory. The age adjusted mean value of total T4 in both men and women was significantly lower in ever workers than in never workers. Coincidentally, the proportion of subjects that had concentrations of total $\mathrm{T} 4$ lower than the reference value $(7.8 \%, n=15)$ was higher in ever than in never workers $(\mathrm{p}<0.01)$. A significant difference was also found for the mean value of GGT between male ever and never workers, with a higher mean among male ever workers that did not vary after adjusting for alcohol intake. All subjects with GGT concentrations higher than the reference value $(n=13)$ were ever worker men. Overall, 16 subjects $(8.3 \%)$ had GGT concentrations above the reference value.

In a crude analysis, HCB was associated with total T4, ALT, and GGT and PCB was associated with TSH (table 3). These correlations did not change after adjusting for total lipid content. Pearson correlation coefficient between HCB and lipid adjusted HCB was 0.95 $(\mathrm{p}<0.01)$, and between PCB and lipid adjusted PCB it was $0.97(\mathrm{p}<0.01)$.

Table 4 presents the adjusted association between HCB and PCB concentrations and the thyroid and liver biomarkers. No significant

Table 3 Crude Pearson's correlation coefficients between concentrations of serum organochlorine compounds (ln HCB and ln PCBs in ng/ml), thyroid hormones, and liver enzymes

\begin{tabular}{lllllll}
\hline & Ln TSH & Total T4 & Free T4 & Ln AST & Ln ALT & Ln GGT \\
\hline Ln HCB & -0.08 & $-0.28^{\star \star \star}$ & 0.02 & 0.10 & $0.17 \dagger$ & $0.34^{\star \star \star}$ \\
Ln PCBs & $-0.07^{\star}$ & -0.01 & 0.09 & 0.03 & 0.05 & 0.19 \\
\hline
\end{tabular}

${ }^{\star} \mathrm{p}=0.05 ; \mathrm{tp}=0.02 ;{ }^{\star \star \star} \mathrm{p}<0.001$

$\mathrm{Ln}=$ natural logarithmic transformation. association was found for TSH, free T4, AST, and ALT after adjusting for sex, age, body mass index, alcohol consumption, and occupation in the electrochemical factory. A significant negative association was found between total $\mathrm{T} 4$, the three quartiles of $\mathrm{HCB}$ and the first quartile of PCBs. The association was significant for $\mathrm{HCB}$ as a continuous variable, but not for PCBs. Similarly, a significant positive association was also found between GGT and the third quartile of $\mathrm{HCB}$ and the third quartile of PCB and between GGT and HCB as a continuous variable. No differences in these results were found after adjustment for total lipids. The associations between HCB and total T4 and GGT were independent of the PCB concentrations and no interaction was found between $\mathrm{HCB}$ and PCB concentrations $(p>0.5)$. Other organochorinated compounds, such as dichlorodiphenyldichloroethane ( $p, p-$ $\mathrm{DDE})$, or $\beta$-hexachlorocyclohexane (b-HCH) did not confound the association with HCB. For GGT, the significant interaction found between occupation and sex (higher concentrations of GGT in men than in women among ever workers, table 2, $(p=0.02))$ disappeared after adjusting for HCB serum concentrations in the multiple regression model, which did not happen after adjusting for PCB concentrations. Finally, no interaction was found between HCB and occupation in the electrochemical factory nor between $\mathrm{HCB}$ and alcohol relative to GGT concentrations.

\section{Discussion}

This is the first study evaluating the association between clinical markers of thyroid and liver function and concentrations of HCB in serum in a sample of the general population. The population under study is the one with the highest concentration of this compound ever reported. An association between HCB and 
Table 4 Regression coefficients of the adjusted associations between serum concentrations of thyroid stimulating hormone (TSH), thyroxine (total T4 and free T4), aspartate aminotransferase (AST), alanine aminotransferase (ALT), and glutamyl transpeptidase (GGT), and serum concentrations of HCB and PCB in quartiles (model 1) and as continuous variable (model 2)

\begin{tabular}{|c|c|c|c|c|c|c|c|c|c|c|}
\hline \multirow{3}{*}{$\frac{\text { Variables }}{\text { Referencet }}$} & \multicolumn{10}{|c|}{ Coefficient (SE) } \\
\hline & \multicolumn{2}{|c|}{$\ln (T S H)$} & \multirow{2}{*}{$\frac{T_{\text {Total T4 }}}{8.56(0.34)}$} & \multicolumn{2}{|l|}{ Free T4 } & \multicolumn{2}{|c|}{$\ln (A S T)$} & \multicolumn{2}{|c|}{$\ln (A L T)$} & \multirow{2}{*}{$\frac{\ln (G G T)}{2.43(0.12)}$} \\
\hline & 0.36 & $(0.07)$ & & 1.34 & $(0.04)$ & 2.89 & $(0.05)$ & 2.32 & $(0.09)$ & \\
\hline \multirow{2}{*}{\multicolumn{11}{|c|}{$\begin{array}{l}\text { Model 1: } \\
\text { Ouartiles } \operatorname{HCB}(\mathrm{ng} / \mathrm{ml}) \text { : }\end{array}$}} \\
\hline & & & & & & & & & & \\
\hline $9.8-12.5$ & -0.02 & $(0.08)$ & $-0.80(0.37)^{\star}$ & -0.08 & $(0.04)$ & 0.02 & $(0.06)$ & -0.08 & $(0.10)$ & $-0.03(0.13)$ \\
\hline $12.5-16.5$ & -0.01 & $(0.09)$ & $-0.85(0.41)^{\star}$ & -0.06 & $(0.05)$ & 0.04 & $(0.07)$ & 0.02 & $(0.11)$ & $0.21(0.14)$ \\
\hline 16.5 & -0.11 & $(0.07)$ & $-1.16(0.38)^{\star}$ & -0.04 & $(0.05)$ & 0.00 & $(0.06)$ & 0.01 & $(0.11)$ & $0.22(0.13)^{\star}$ \\
\hline \multicolumn{11}{|c|}{ Quartiles PCBs (ng/ml): } \\
\hline $1.3-2.6$ & -0.02 & $(0.07)$ & $-0.66(0.31)^{\star}$ & -0.01 & $(0.04)$ & 0.03 & $(0.05)$ & 0.04 & $(0.08)$ & $0.18(0.11)$ \\
\hline $2.6-5.0$ & -0.07 & $(0.08)$ & $-0.47(0.33)$ & -0.01 & $(0.04)$ & 0.01 & $(0.05)$ & 0.05 & $(0.09)$ & $0.15(0.11)$ \\
\hline$>5.0$ & -0.01 & $(0.09)$ & $-0.07(0.33)$ & 0.02 & $(0.04)$ & 0.05 & $(0.05)$ & 0.05 & $(0.09)$ & $0.30(0.11)^{\star}$ \\
\hline \multicolumn{11}{|l|}{ Model 2: } \\
\hline $\mathrm{Ln}(\mathrm{HCB}) \mathrm{ng} / \mathrm{ml} \neq$ & -0.02 & $(0.03)$ & $-0.32(0.11)^{\star}$ & -0.01 & $(0.01)$ & 0.00 & $(0.02)$ & 0.02 & $(0.03)$ & $0.10(0.04)^{\star}$ \\
\hline $\mathrm{Ln}(\mathrm{PCB}) \mathrm{ng} / \mathrm{ml} \ddagger$ & 0.005 & $(0.03)$ & $-0.01(0.09)$ & 0.007 & $(0.01)$ & 0.00 & $(0.01)$ & 0.002 & $(0.02)$ & $0.05(0.03)$ \\
\hline
\end{tabular}

${ }^{\star} \mathrm{p}<0.05$.

†Reference category (SE): mean concentrations for women of 46 years old and $24 \mathrm{~kg} / \mathrm{m}^{2}$ of body mass index, without alcohol consumption, who had never been working in the electrochemical factory and with HCB and PCB serum concentrations lower than 9.8 $\mathrm{ng} / \mathrm{ml}$ and $1.3 \mathrm{ng} / \mathrm{ml}$, respectively.

‡Adjusted change for each unit change in $\ln$ HCB or $\ln$ PCB, adjusted by sex, age, body mass index, and alcohol consumption. The model includes both HCB and PCB concentrations as continuous variable.

concentrations of total T4 and GGT, independent of PCB concentrations, was found. No effects associated with $\mathrm{HCB}$ concentrations were found for TSH, free T4, AST, and ALT. These results did not change after correction of the concentrations of organochlorine compounds and total lipid content. A less consistent association with GGT was found for PCBs.

The present results show no effect on TSH and free T4 concentrations but a diminution of total $\mathrm{T} 4$ associated with serum concentrations of HCB. The mechanism postulated for the effects of HCB on the thyroid encompass accelerated metabolism of thyroid hormones by HCB induced enzymes or accelerated deionidation of T4, and interference with plasma transport of thyroid hormones through displacement of $\mathrm{T} 4$ from binding sites on proteins. ${ }^{20} 21$ Several studies in animals have shown a decrease of total $\mathrm{T} 4$ concentrations, ${ }^{1022}{ }^{23}$ and, to a lesser extent of T3 without affecting TSH concentrations after exposure to HCB. Somewhat different effects (decreased T3 and no change on T4) have also been reported. ${ }^{9}$ In humans, very few studies have considered the relation between HCB and thyroid hormones.

In the Turkish outbreak, concentrations of thyroid hormones were never measured, but higher incidence of goitre was reported. ${ }^{12} \mathrm{Maz}-$ hitova et $a l^{4}$ did not find any association between chlorinated contaminants, which included HCB, and thyroid hormones in schoolchildren form the Aral Sea region. Reduction in plasma T4 concentrations, however, has been described after exposure to $\mathrm{PCBs}^{25-27}$ and dioxins. ${ }^{28}$ The association found between total T4 and the first quartile of PCB did not confound the association with $\mathrm{HCB}$ in the multivariate analysis. Although most of the studies show an effect of exposure to organochlorine compounds on the thyroid hormones, the lack of consistency in the results may reflect differences in susceptibility among chemical species or populations as well as differences in exposure. On the other hand, it should be taken into account that there are compensatory mechanisms that can result in the normalisation of serum concentrations of thyroid hormone ${ }^{29}$ upon longer exposure times.

The present results suggest that HCB causes a subtle effect on thyroid function. This effect could have some implications in a more susceptible population such as newborn infants. Thyroxine is the main thyroid hormone that influences the thyroid dependent neurodevelopment. ${ }^{30}$ Altered thyroid hormone concentrations may play an important part in the maturation of the foetal or neonatal central nervous system, which is particularly sensitive to environmental pollutants. ${ }^{31}$

Regarding the results of liver enzymes, there is a positive adjusted association between HCB and GGT concentrations. The mean value of GGT was higher among ever than never workers. This difference was independent of alcohol consumption. Two preceding studies on workers from chlorinated solvent factories have shown an association between HCB and markers of liver function. ${ }^{32} 33$ PCB had been associated with GGT in some human studies. ${ }^{34-36}$ In the present case, there is also a relation with PCB. However, PCB does not confound the association between HCB and GGT in the multivariate analysis, nor in the stratified analysis (not shown). Similarly, other organochorine compounds, such as p,p-DDE, or b- $\mathrm{HCH}$ did not confound the association with HCB.

Furthermore, workers are characterised by high concentrations of $\mathrm{HCB}$, whereas concentrations of the other common organochlorinated compounds are in the range of those found in other places. ${ }^{13}$ In the present case, no association between HCB or PCBs and transaminases was found, indicating no damage on the hepatocyte. Several studies in animal laboratories have reported an induction of various enzymes after exposure to HCB. ${ }^{37}{ }^{38}$ Increased GGT can be found in situations of induction of enzymatic activity due to certain drugs such as phenobarbital or alcohol consumption. The association with GGT found in this study, is not due to 
alcohol consumption, and may indicate induction of enzymatic activity.

Recently it has been suggested that HCB should be classified as a dioxin-like compound that binds the aryl hydrocarbon receptor. ${ }^{1}$ This property may explain, in part, its mechanisms of action. Hexachlorobenzene is a mixed type inducer with effects such as induction of activity of hepatic cytochrome p4502B (CYP2B). According to in vitro experiments, $\mathrm{HCB}$ binds to the aryl hydrocarbon receptor about 10000 times less than 2,3,7,8tetrachlorodibenzo-p-dioxin. It has been estimated that HCB could add $10 \%-60 \%$ to the total toxic equivalents (TEQs) in human milk samples. ${ }^{1}$

A strong correlation between internal dose of HCB and the formation of mercapturic acid derivatives in urine was found in a previous study. ${ }^{18}$ The formation of glutathione conjugates may play a significant part in HCB detoxification within this range of human accumulation of HCB. This detoxification mechanism may avoid some of the clinical effects described in laboratory animals or in the Turkish outbreak, such as alterations in porphyrin metabolism.

The low response rate among the subjects from a random sample who were asked to provide biological samples constitutes a limitation of the study. Blood and urine from volunteers were also accepted to increase the numbers of available samples. As described elsewhere, ${ }^{14}$ no differences in socioeconomic, occupational, and health status, nor in HCB concentrations, were found between subjects from the random sample and volunteers. The proportion of current workers included in the study was similar to the proportion of current workers in the general population of Flix. Similarly, no differences in health were found among the study population and the reference population from the Catalan National Health Survey. ${ }^{13}$ These arguments suggest that the association between the biomarkers of exposure and effect are not biased by non-response. Confounding for other environmental exposures such as dioxins could not be discounted. Information on individual concentrations of dioxins in this population is not available, but the total dioxin equivalents in the area fulfil the ambient air quality standard for no notable health effects. ${ }^{39}$

In conclusion, the decrease of total $\mathrm{T} 4$ and the increase of GGT concentrations associated with serum concentrations of $\mathrm{HCB}$, although within the normal reference values, may indicate an induction of enzymatic activity of HCB and suggest a subtle metabolic effect on thyroid and liver function. Little is known of the deleterious effects in humans of $\mathrm{HCB}$, which is one of the most common organochlorine products found in human tissues. Further studies are needed to better understand the mechanisms of action of HCB and evaluation of the role of these effects in more susceptible populations such as infants.
1 van Birgelen APJM. Hexachlorobenzene as possible major contributor of the dioxin-activity of human milk. Environ Health Perspect 1998;106:683-8.

2 Cabral JRP, Shubik P, Mollner T, et al. Carcinogenic activity of hexaclorobenzene in hamsters. Nature 1977;269:51011 .

3 Cabral JRP, Mollner T, Raitano F, et al. Carcinogenesis of hexachlorobenzene in mice. Int $\mathcal{F}$ Cancer 1979;23:47-51.

4 Schmid R. Cutaneous porphyria in Turkey. $N$ Engl 7 Med 1960;263:397-8.

5 Cam C, Nigogosyan G. Acquired toxic porphyria cutanea tarda due to hexachlorobenzene. $\mathscr{f} A M A$ 1963;183: $88-91$.

6 Foster WG, McMahon A, Villeneuve DC, et al. Hexachlorobenzene (HCB) suppresses circulating progesterone concentrations during the luteal phase in the cynomolgus monkey. F Appl Toxicol 1992;12:13-17.

7 Jarrell J, McMahon A, Villeneuve D, et al. Hexachlorobenzene toxicity in the monkey primordial germ cell without induced porphyria. Reprod Toxicol 1993;7:41-7.

8 van Raaij JA, Kaptein E, Visser TJ, et al. Increased glucuronidation of thyroid hormone in hexachlorobenzene-treated rats. Biochem Pharmacol 1993;45:627-31.

9 Smith A, Dinsdale D, Cabral J, et al. Goitre and wasting induced in hamsters by hexachlorobenzene. Toxicology 1987;60:343-9.

10 van Raaij JAGM, Frijters CMG, van den Berg JK. Hexachlorobenzene-induced hypothyroidism. Involvement of different mechanisms by parent compound and metabolite. Biochem Pharmacol 1993;46:1385-91.

11 Manson MM, Smith AG. Effect of hexachlorobenzene on male and female rat hepatic $\gamma$-glutamyl transpeptidase levels. Cancer Lett 1984;22:227-34.

12 Gocmen A, Peters H, Cripps D, et al. Hexachlorobenzene episode in Turkey. Biomed Environ Sci 1989;2:36-43.

13 Sala M, Sunyer J, Otero R, et al. Organochlorine compound concentration in the serum of inhabitants living near an electrochemical factory. Occup Environ Medicine 1999;56: 152-6.

14 Sala M, Sunyer J, Otero R, et al. Health effects of chronic high exposure to hexachlorobenzene in a general population sample. Arch Environ Health 1999;54:102-9

15 Colborn T. Environmental estrogens: health implications for humans and wildlife. Environ Health Perspect 1995; 103(suppl 7):135-6.

16 Colborn T. The wildlife/human connection: modernizing risk decisions. Environ Health Perspect 1994;102(suppl 12): $55-9$.

17 Herrero C, Ozalla D, Sala M, et al. Urinary porphyrin excretion in a human population highly exposed to hexachlorobenzene. Arch Dermatol 1999;135:400-4.

18 To-Figueras J, Sala M, Otero R, et al. Metabolism of hexachlorobenzene in humans: association between serum levels and urinary metabolites in a highly exposed populalevels and urinary metabolites in a highly exp

19 Phillips DL, Pirkle JL, Burse VW, et al. Chlorinated hydrocarbon levels in human serum: effects of fasting and feeding. Arch Environ Contam Toxicol 1989;18:495500 .

20 van Raaij JA, Frijters CM, van den Berg KJ. Hexachlorobenzene-induced hypothyroidism. Involvement of different mechanisms by parent compound and metabolite. Biochem Pharmacol 1993;46:1385-91.

21 Visser TJ, Kaptein E, van Toor H, et al. Glucuronidation of thyroid hormone in rat liver: effects of in vivo treatment with microsomal enzyme inducers and in vitro assay condiwith microsomal enzyme inducers and in

22 van Raaij JA, van den Berg KJ, Notten WR. Hexachlorobenzene and its metabolites pentachlorphenol and tetrachlorohydroquinone: interaction with thyroxine binding sites of rat thyroid hormone carriers ex vivo and in vitro. Toxicol Lett 1991;59:101-7.

23 Foster WG, Pentick JA, McMahon A, et al. Body distribution and endocrine toxicity of hexachlorobenzene (HCB) in the female rat. 7 Appl Toxicol 1993;13:79-83.

24 Mazhitova Z, Jensen S, Ritzen M, et al. Chlorinated contaminants, growth and thyroid function in schoolchildren from the Aral Sea region in Kazakhstan. Acta Paediat
1998;87:991-5. Koopman-Esseboom C, Morse DC, Weisglas-Kuperus N, et al. Effects of dioxins and polychlorinated biphenyls on thyroid hormone status of pregnant women and their infants. Pediatr Res 1994;36:468-73.

26 Emmett EA, Maroni M, Jefferys J, et al. Studies of Emmett EA, Maroni M, Jefferys J, et al. Studies of
transformer repair workers exposed to PCBs: II. Results of transformer repair workers exposed to PCBs: II. Results of clinical $47-62$.

27 Nagayama J, Okamura K, Iida T, et al. Postanatal exposure to chlorinated dioxins and related chemicals on thyroid hormone status in Japanese breast-fed infants. Chemosphere 1998;37:1789-1793.

28 Pluim HJ, de Vijlder JJM, Olie K, et al. Effects of pre- and postnatal exposure to chlorinated dioxins and furans on human neonatal thyroid hormone concentrations. Environ Healht Perspect 1993;101:504-8.

29 DeVito M, Biegel L, Brouwer A, et al. Screening methods for thyroid hormone disruptors. Environ Health Perspect 1999;107:407-15.

30 Calvo R, Obregon MJ, Ruiz de Ona C, et al. Congenital hypothyroidism, as studied in rats. Crucial role of maternal thyroxine but not of 3,5,3'-triiodothyronine in the protection of the fetal brain. $\mathcal{F}$ Clin Invest 1990;86: in the prote $889-99$. 
31 Colborn T. Pesticides: how research has succeeded and failed to translate science into policy: endocrinological effects on wildlife. Environ Health Perspect 1995;103(suppl 6):81-5.

32 Currier MF, Mcclimans CD, Barna-Lloyd G. Hexachlorobenzene blood levels and the health status of men employed in the manufacture of chlorinated solvents. $\mathcal{F}$ Toxicol Environ Health 1980;6:367-77.

33 Seldén AI, Nygren Y, Westberg HB, et al. Hexachlorobenzene and octachlorostyrene in plasma of aluminium foundry workers using hexachloroethane for degassing. Occup Environ Med 1997;54:613-18.

34 Smith AB, Schloemer J, Lowry LK, et al. Metabolic and health consequences of occupational exposure to polychlorinated biphenyls. Br F Ind Med 1982;39:361-9.
35 Emmett EA, Maroni M, Jefferys J, et al. Studies of transformer repair workers exposed to PCBs:II. Results of clinical laboratory investigations. Am f Ind Med 1988;14: 47-62

36 Feely MM. Biomarkers for Great Lakes priority contaminants: halogenated aromatic hydrocarbons. Environ Health Perspect 1995;103(suppl 9):7-16.

37 Courtney K. Hexachlorobenzene (HCB): a review. Environ Res 1979;20:225-66.

38 Smith AG, Carthew P, Francis JE, et al. Enhancement by iron of hepatic neoplasia in rats caused by hexachlorobenzene. Carcinogenesis 1993;14:1381-7.

39 Grimalt JO, Sunyer Deu J, Moreno V, et al. Risk excess of softtissue sarcoma and thyroid cancer in a community exposed to airborne organochlorinated compound mixtures with a high hexachlorobenzene content. Int $\mathcal{F}$ Cancer 1994;56:200-3.

\section{Open reviewing}

Many journals, including the BMJ, have moved to a system of open reviewing, whereby authors know the names of reviewers of their papers. Research has shown that named reviews, although not of better quality than anonymous reviews, are not of worse quality either. Therefore in the interests of transparency, it seems fair to let authors know who has reviewed their paper. At Occupational and Environmental Medicine we have considered the issue carefully. There are some concerns that reviewers, especially those who are more junior, might feel intimidated and not wish to make negative comments about papers submitted by senior people in the field. On the other hand, some reviewers might hide behind the cloak of anonymity to make unfair criticisms so as to reduce the chances of publication by rivals. We have decided to introduce initially a system of open reviewing if the reviewers agree explicitly. So when a reviewer is sent a paper, he or she is asked to indicate whether we can disclose their name or not when sending the authors their comments. We will be monitoring this to see how many of our reviewers are happy to be named. If it is most of them, we will move to a system of open reviewing as the norm, with a possible "opt out" clause for reviewers. 